\title{
Cartographic sources for the reconstruction of the Syro- Palestinian landscape in the Late Antiquity
}

\author{
Margherita Azzari ${ }^{\text {a }}$, Carmelo Pappalardo a , Anna Lena ${ }^{\text {a }}$ \\ ${ }^{a}$ University of Florence, Department of History, Archaeology, Geography, Arts and Performing Arts, margherita.azzari@unifi.it , \\ carmelo.pappalardo@unifi.it \\ * Corresponding author
}

Keywords: Historical cartography, historical landscape, virtual landscaping, Holy Land

\begin{abstract}
:
This paper intends to present a project carried out by Labgeo of the University of Florence, under the patronage of the Italian Ministry of Foreign Affairs, on the Madaba Map and aimed at the reconstruction of the historical landscape of the syro-palestinian area during the Late Antiquity. The project is currently focusing on the processing of data acquired in the area of the east side of the Jordan Valley, the Dead Sea and of the Ghor till Aqaba/Eilat to develop a re-usable methodology.
\end{abstract}

The Madaba Mosaic Map is a detailed mosaic floor representation of the geography of the Holy Land from the Nile Delta to Lebanon and from the desert to the Mediterranean Sea and was made both for the local community and for the pilgrims that, between the 4th and 7th century CE journeyed to the Holy Land. The mosaic is mostly a unique geographical and historical document created with all the knowledge and cartographical techniques that had evolved over the centuries of the Roman and Byzantine Empires. In the Madaba map the geographical components are represented in their correct spatial relationship and selected on the basis of their relevance for different purposes, symbolic and functional; the territory is represented using a composite plot of nodes and paths; it can be read in a variety of ways (as a roadmap, from a symbolic or artistic point of view); it offers a dynamic and static reading of the territory.

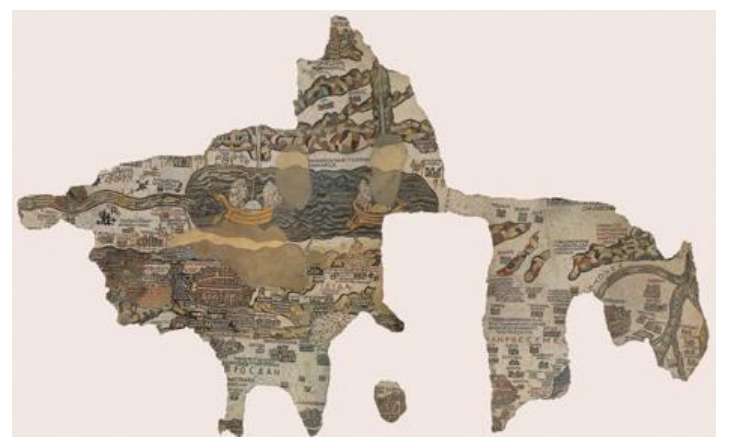

Figure 1. The Madaba mosaic Map.

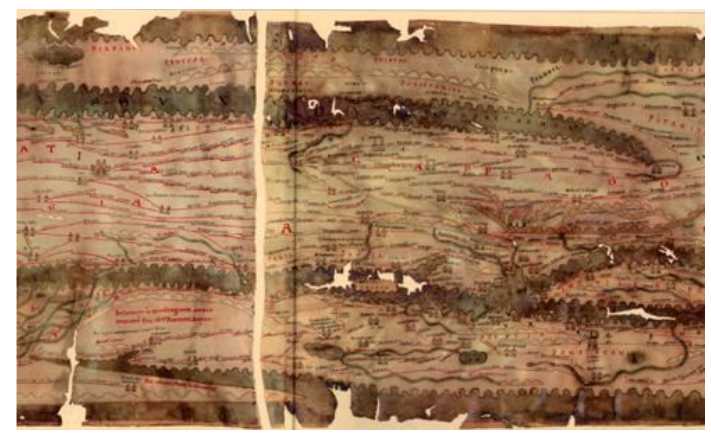

Figure 2. Part of seg. IX and X of the Tabula Peutingeriana

The general aims of the research are:

1. to deconstruct and analyse the Madaba Mosaic Map, using a geo historical approach and interpretative keys (tangible vs intangible culture; biblical vs geographical knowledge) with reference to a variety of sources (cartographic, iconographic, archaeological, epigraphic, artistic, documentary) and to its geographical, cultural and socio-economic context;

2. to reconstruct the historical landscape (physical and anthropic) on the basis of the Madaba Mosaic Map that portrays the biblical landscape as well as the physical geographical characteristics of the territory; one of the pivotal point of the project is the reconstruction of the road network as the area depicted on the map was crossed by several trade routes large arteries or smaller peripheral routes - which connected Egypt to the coast of Phoenicia, to the Syrian plateau as far as the Arabian peninsula and which were crossed by men, goods, ideas and cultures. 
3. to virtually restore the missing parts of the mosaic and to create $3 \mathrm{D}$ immersive scenarios of the represented landscapes using virtual landscaping;

4. to virtually reassemble the map using interaction design strategies and augmented reality technologies to improve its understanding and to optimize the possibilities of interpretation, comparison, sharing with attention to different types of users;

5. to create a digital archive to preserve and disseminate georeferenced data, bibliographic resources and other contents related to the topic.

The methodology used for the reconstruction of past territorial systems is part of the broad context of the Spatial Humanities (Bodenhamer, Corrigan, Harris 2010; Gregory, Geddes 2014; Dunn 2017). This interdisciplinary research strategy involves the integration of methods and tools from GIS with the sources and questions of archaeological and geo-historical research, in the awareness of the importance of reconstructing spatial contexts and relationships for understanding historical dynamics. The use of GIS allows the acquisition of information layers from inhomogeneous sources in an environment suitable for their management, analysis and visualization aimed at the reconstruction of the history of the landscape and of the political-administrative, geographical, socio-economic context, making it possible to associate the spatial data and qualitative information relating to the economic and demographic dynamics that characterized the broad historical period considered.

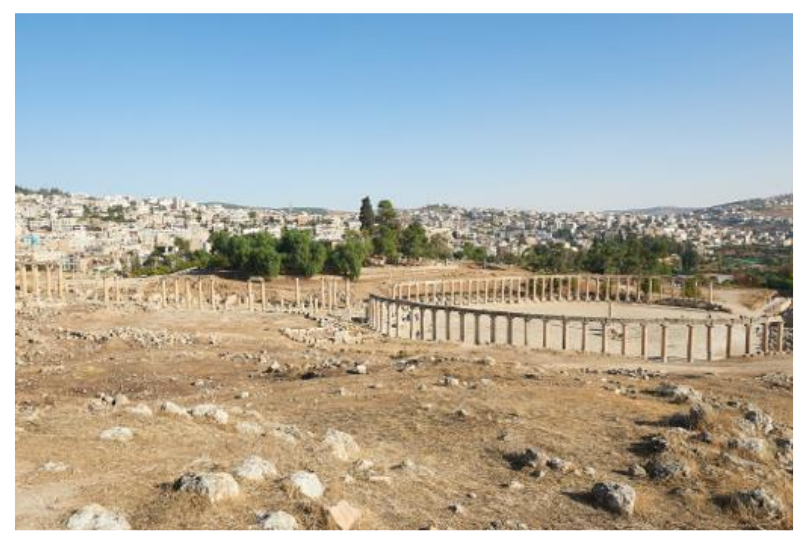

Figure 3. The City of Jerash.

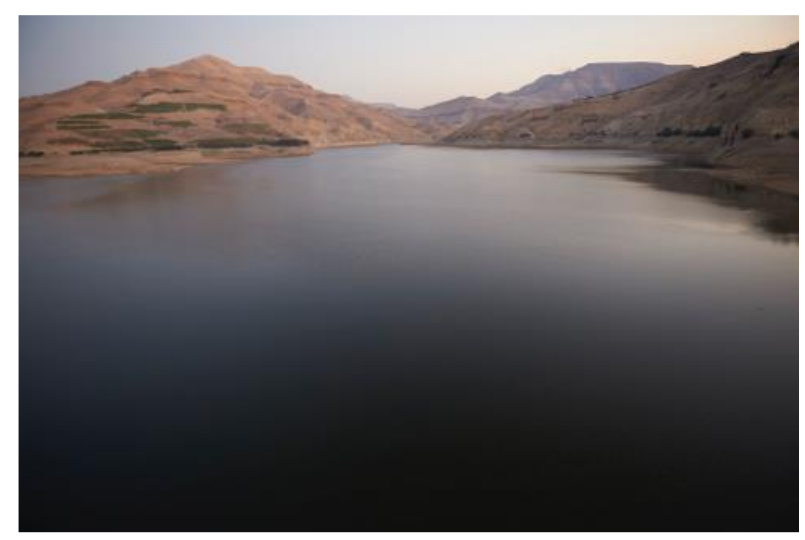

Figure 4. The Mujib-Arnoun dam reservoir

A comparative study of the sources allows strategic acquisition for a stratigraphic analysis of the mosaic Map of Madaba and the realization of the subsequent research phases. The main source is the Tabula Peutingeriana, a 12th century copy of a road map probably designed in the first half of the 4th century, that outlines the main streets of the Roman Empire. Another source to be consider is Ptolemy's Geography with its set of cartographies (whose authenticity is discussed) that, as can be deduced from a passage from Cassiodorus (Institutiones divinarum et humanarum rerum, approx. 544), still circulated in the 6th century. To evaluate the legacy of the Madaba Mosaic Map, we have to consider a wider cartographic context which comprises Arab and European cartographies. Medieval cartography and modern cartography. The correspondence between Byzantine pilgrim reports (see Archdeacon Theodosius, 518-530 CE; Pilgrim of Bordeaux, 333 CE; Egeria, 381-384 CE; Anonimous from Piacenza 570 CE, Breviarius de Hierosolyma, 550 $\mathrm{CE}$, etc.) and the notes recurring on the map, suggest the existence of biblical-geographical maps borrowed from the Roman military cartography. Another important source is the Onomasticon of Eusebius of Caesarea (approx. 265-339) where the biblical places are listed and described and which was translated from Greek to Latin by Jerome around 385 (Liber locorum et nominum). It is furthermore evident the influence of the Roman itineraria (adnotata or picta), including lists of stations and distances (see Itinerarium Gaditanum, 1st century; Dura Europos map, 260 CE, a fragment of the cover of a decorated shield with an itinerarium pictum connected with military operations; Itinerarium Antonini, 4th century; Itinerarium Burdigalense, $333 \mathrm{CE}$;). The Notitia Dignitatum, a document of the late Roman Empire that details the administrative organization of the Eastern and Western parts of the Empire it is another source that has many parallels with the Madaba Map and was probably a key reference for it.

The implementation of a GIS able to manage historical series of data to reconstruct a landscape, the morphology of the territory, the hydrographic network, the settlement system, the distribution of crops, the road network, the defensive system highlighting also the transformation processes, represents an exportable and reusable methodology also to manage multi-source data (RT3D) in a 3D environment and virtually restore cartographic/iconographic documents. 